\title{
Glucose-Nonfermenting Gram-Negative Bacilli Associated with Clinical Veterinary Specimens
}

\author{
JOHN J. MATHEWSON†* AND RUSSELL B. SIMPSON \\ Department of Veterinary Microbiology and Parasitology, Texas A \& M University, College Station, Texas \\ 77843
}

Received 16 November 1981/Accepted 29 January 1982

\begin{abstract}
Glucose-nonfermenting gram-negative bacilli (NFB) have been recognized recently as opportunistic pathogens of humans. With few exceptions, strains of NFB have not been considered important enough to be identified when isolated from animals. In this study, all NFB isolated during a 1-year period in a clinical veterinary microbiology laboratory were identified to determine their prevalence. Of the 347 strains of NFB obtained, the most common species were Pseudomonas aeruginosa, Acinetobacter calcoaceticus, Bordetella brochiseptica, and Pseudomonas pseudoalcaligenes. Of all clinical veterinary specimens submitted for cultures, $10 \%$ contained nonfermenters.
\end{abstract}

Glucose-nonfermenting gram-negative bacilli (NFB) have had much attention recently in human medicine $(5,10,15,16)$. Most species of NFB were once thought to be contaminants when cultured from human specimens, but many have been shown to be opportunistic pathogens of humans $(4,8,13)$.

In veterinary medicine, however, glucosenonfermenting species are not considered to be animal pathogens. Most veterinary microbiology laboratories do not routinely identify NFB other than Pseudomonas aeruginosa, Bordetella bronchiseptica, and Moraxella bovis. For this reason, little is known about NFB associated with clinical specimens from animals or their role in animal disease.

This study was undertaken to determine the identity and the prevalence of glucose-nonfermenting species in clinical veterinary specimens submitted to our laboratory during a 1-year period. It was hoped that this would be a first step in determining the role of these organisms in infections of animals.

\section{MATERIALS AND METHODS}

Clinical isolates of NFB. All strains of NFB isolated in the Clinical Microbiology Laboratory of Texas A \& $M$ University Teaching Hospital between 1 January 1980 and 1 January 1981 were collected for identification. Information concerning animal species, specimen type, clinical history, and other bacteria isolated was recorded for each isolate of NFB.

Identification of isolates of NFB. The isolates of NFB were identified with a series of 30 conventional identification tests which were prepared, performed, and

† Present address: The University of Texas Health Science Center at Houston-Medical School, Program in Infectious Diseases and Clinical Microbiology, Houston, TX 77025. interpreted according to recognized methods (9-11, $16,17)$. Unless specifically noted, all identification tests were incubated aerobically at $35^{\circ} \mathrm{C}$ and interpreted at 24,48 , and $96 \mathrm{~h}$. The following identification tests were performed on each unknown isolate: OF dextrose, OF lactose, OF maltose, OF xylose, OF fructose, OF mannitol, OF galactose, OF rhamnose, OF mannose, cytochrome oxidase, hemolysis, nitrate reduction (to nitrite or nitrogen gas or both), lysine and ornithine decarboxylase, arginine dihydrolase, esculin hydrolysis, citrate utilization, DNase, hydrogen sulfide production, indole production, $o$-nitrophenylbeta-D-galactopyranosidase, growth on MacConkey agar, growth on salmonella-shigella agar, growth on cetrimide agar, growth at $42^{\circ} \mathrm{C}$, pigment production $\left(25^{\circ} \mathrm{C}\right)$, motility $\left(25^{\circ} \mathrm{C}\right)$, and flagellar morphology. The identification of each isolate was made by comparing the results of these tests with published reactions for all species of NFB $(5-7,10,15,18)$.

Quality control for identification system. The reliability of the identification system was tested to ensure that these tests could accurately identify isolates of NFB. Twenty-seven known strains of NFB (22 species) were obtained from G. L. Gilardi (Hospital for Joint Diseases, New York). These known isolates were tested with the previously described set of identification tests. The identification of each known isolate obtained with our system was compared with that made by Gilardi. In each case, the identifications were the same.

\section{RESULTS}

Glucose nonfermenters were isolated from $347(10 \%)$ of the 3,474 specimens submitted to the clinical microbiology laboratory during the 1-year study period. Six genera of NFB were found in the veterinary specimens (Table 1). Pseudomonas was the most prevalent species of glucose nonfermenters, accounting for $76.9 \%$ of all strains recovered. Acinetobacter (14.5\%) was next in frequency, followed by Bordetella 
TABLE 1. Prevalence of 347 strains of NFB in 3,474 clinical veterinary specimens

\begin{tabular}{|c|c|c|c|c|c|c|}
\hline \multirow{2}{*}{ Species (no.) } & \multirow{2}{*}{$\begin{array}{l}\% \text { All } \\
\text { isolates }\end{array}$} & \multicolumn{5}{|c|}{ No. of isolates from: } \\
\hline & & Equine & Canine & Bovine & Feline & Other ${ }^{a}$ \\
\hline Pseudomonas aeruginosa (233) & 67.4 & 111 & 104 & 4 & 8 & 7 \\
\hline Acinetobacter calcoaceticus $(50)$ & 14.5 & 27 & 17 & 2 & 2 & 2 \\
\hline Bordetella bronchiseptica (17) & 4.9 & 8 & 9 & 0 & $\mathbf{0}$ & 0 \\
\hline Pseudomonas pseudoalcaligenes (8) & 2.3 & 7 & 0 & 0 & 0 & 1 \\
\hline Pseudomonas stutzeri (5) & 1.4 & 1 & 2 & 2 & 0 & 0 \\
\hline Pseudomonas maltophilia (4) & 1.2 & 3 & 0 & 1 & 0 & $\mathbf{0}$ \\
\hline Pseudomonas alcaligenes (4) & 1.2 & 3 & 1 & 0 & 0 & 0 \\
\hline Pseudomonas putida (4) & 1.2 & 3 & 0 & 1 & 0 & 0 \\
\hline Moraxella phenylpyruvica (4) & 1.2 & 1 & 3 & $\mathbf{0}$ & 0 & $\mathbf{0}$ \\
\hline CDC M-5 (3) & 0.9 & 0 & 3 & 0 & 0 & $\mathbf{0}$ \\
\hline Alcaligenes faecalis (2) & 0.6 & 1 & 0 & 1 & $\mathbf{0}$ & 0 \\
\hline Pseudomonas fluorescens (2) & 0.6 & 1 & 0 & 1 & $\mathbf{0}$ & $\mathbf{0}$ \\
\hline Pseudomonas diminuta (2) & 0.6 & 2 & 0 & 0 & 0 & 0 \\
\hline Pseudomonas testosteroni (2) & 0.6 & 0 & 0 & 2 & 0 & 0 \\
\hline Pseudomonas putrefaciens (1) & 0.3 & 0 & 0 & 0 & 0 & 1 \\
\hline CDC VE-2 (1) & 0.3 & 1 & 0 & 0 & 0 & 0 \\
\hline CDC IIF (1) & 0.3 & $\mathbf{0}$ & 0 & 0 & 0 & 1 \\
\hline Alcaligenes odorans (1) & 0.3 & $\mathbf{0}$ & 1 & 0 & 0 & 0 \\
\hline Moraxella nonliquifaciens (1) & 0.3 & $\mathbf{0}$ & 1 & 0 & 0 & 0 \\
\hline Pseudomonas sp. (1) & 0.3 & 1 & 0 & 0 & 0 & 0 \\
\hline
\end{tabular}

${ }^{a}$ Includes specimens from birds, reptiles, pigs, goats, and rabbits.

(4.9\%), Moraxella (2.4\%), Alcaligenes (0.9\%), and Flavobacterium $(0.3 \%)$.

Table 1 also shows the prevalence of the species of NFB cultured from animal specimens. $P$. aeruginosa $(67.4 \%$ ) was the most commonly isolated glucose-nonfermenting species. Acinetobacter calcoaceticus $(14.5 \%)$ was next in frequency, followed by $B$. bronchiseptica $(4.9 \%)$ and Pseudomonas pseudoalcaligenes (2.3\%). Twenty different species of NFB were cultured from the animal specimens.

NFB were found in specimens representing nine animal species (Table 1). Isolates of NFB were cultured most commonly from equine specimens $(49.4 \%)$. Canine samples yielded $40.4 \%$ of all of the isolates. Bovine (3.5\%), feline (2.9\%), and other animal species (3.5\%) provided the remaining isolations of NFB.

\section{DISCUSSION}

Strains of NFB were found in $10 \%$ of the clinical veterinary specimens. This isolation rate indicates that these bacteria may be more prevalent in animal specimens than is generally believed. There are no other reports on the prevalence of NFB species in clinical veterinary materials, but the prevalence of glucose nonfermenters in human specimens has been reported to be 12,15 , and $16 \%(14,16)$.

In this study, $67.4 \%$ of NFB cultured from animals were $P$. aeruginosa, which is comparable to the $66 \%$ reported from human specimens by Pickett (14). The second most prevalent species found in the clinical veterinary speci- mens was Acinetobacter calcoaceticus (14.5\%), which has been reported to be the second most prevalent species of NFB cultured from humans (14).

The third most frequent species of NFB isolated from clinical veterinary materials was $B$. bronchiseptica $(4.9 \%)$. This organism is a recognized pathogen of dogs and swine $(1,2)$. The majority of these isolates were from canine specimens (52.9\%), but it is unusual that $47.1 \%$ of these strains were isolated from equine specimens $(3,12)$. B. bronchiseptica has rarely been reported from human specimens, accounting for less than $1 \%$ of all NFB strains (14).

The data presented on the distribution of glucose-nonfermenting species by animal species were influenced by the rate of specimen submission from the various animal species. In our laboratory, equine and canine specimens accounted for most of the submissions. These distribution data are of interest in that they may reveal general trends about the occurrence of a particular NFB species in animal specimens.

In this investigation, no etiological role was assigned to any of the isolates of NFB. The intent was to determine the prevalence of NFB species associated with veterinary specimens, since there are few reports on the species of NFB isolated from animals. Many of the species that we isolated have not been reported from animals. We have shown that NFB species do occur at a significant rate in animal specimens. Hopefully, this will lead to studies on the possible role of NFB species as animal pathogens. 


\section{ACKNOWLEDGMENTS}

We thank G. L. Gilardi for supplying reference strains of NFB and Barbara Murray for critical review.

\section{LITERATURE CITED}

1. Carter, G. R. 1979. Diagnostic procedures in veterinary bacteriology and mycology, 3rd ed. Charles C Thomas, Publisher, Springfield, Ill.

2. Cottral, G. E. (ed.). 1978. Manual of standardized methods for veterinary microbiology. Cornell University Press, Ithaca, N.Y.

3. Gallagher, G. L. 1965. Isolation of Bordetella bronchiseptica in horses. Vet. Rec. 77:632-633.

4. Gilardi, G. L. 1972. Infrequently encountered Pseudomonas species causing infections in humans. Ann. Intern. Med. 77:211-215.

5. Gilardi, G. L. (ed.). 1978. Glucose nonfermenting gramnegative bacteria in clinical microbiology. CRC Press, West Palm Beach, Fla.

6. Gilardi, G. L. 1978. Identification of miscellaneous glucose nonfermenting gram-negative bacteria, p. 45-65. In G. L. Gilardi (ed.), Glucose nonfermenting gram-negative bacteria in clinical microbiology. CRC Press, West Palm Beach, Fla.

7. Gilardi, G. L. 1978. Identification of Pseudomonas and related bacteria, p. 15-44. In G. L. Gilardi (ed.), Glucose nonfermenting gram-negative bacteria in clinical microbiology. CRC Press, West Palm Beach, Fla.

8. Glew, R. H., R. C. Moellering, and L. J. Kunz. 1977. Infections with Acinetobacter calcoaceticus (Herellea vaginacola): clinical and laboratory studies. Medicine 56:7997.

9. Hugh, R. 1978. Classical methods for isolation and identification of glucose nonfermenting gram-negative rods, $p$. 1-13. In G. L. Gilardi (ed.), Glucose nonfermenting gramnegative bacteria in clinical microbiology. CRC Press, West Palm Beach, Fla.
10. Hugh, R., and G. L. Gillardi. 1980. Pseudomonas, p. 288 317. In E. H. Lennette, A. Balows, W. J. Hausler, Jr. and J. P. Truant (ed.), Manual of clinical microbiology, 3rd ed. American Society for Microbiology, Washington, D.C.

11. MacFaddin, J. F. 1980. Biochemical tests for identification of medical bacteria, 2nd ed. The Williams \& Wilkins Co., Baltimore.

12. Mather, E. C., B. Addison, D. Owens, C. J. Bierschwal, and C. E. Martin. 1973. Bordetella bronchiseptica associated with infertility in a mare. J. Am. Vet. Med. Assoc. 163:76-77.

13. Pedersen, M. M., E. Marso, and M. J. Pickett. 1970 Nonfermentative bacilli associated with man. III. Pathogenicity and antibiotic susceptibility. Am. J. Clin. Pathol. 54:178-192.

14. Pickett, M. J. 1978. New methodology for identification of nonfermenters: rapid methods, p. 155-170. In G. L. Gilardi (ed.), Glucose nonfermenting gram-negative bacteria in clinical microbiology. CRC Press, West Palm Beach, Fla.

15. Pickett, M. J., and M. M. Pedersen. 1970. Characterization of sacchroloytic nonfermentative bacteria associated with man. Can. J. Microbiol. 16:351-362.

16. Rubin, S. J., P. A. Granato, and B. L. Wasilauskas. 1980 Glucose-nonfermenting gram-negative bacteria, p. 263287. In E. H. Lennette, A. Balows, W. J. Hausler, Jr., and J. P. Truant (ed.), Manual of clinical microbiology, 3rd ed. American Society for Microbiology, Washington, D.C

17. Vera, H. D., and D. A. Power. 1980. Culture media, p. 965-999. In E. H. Lennette, A. Balows, W. J. Hausler, Jr., and J. P. Truant (ed.), Manual of clinical microbiology, 3rd ed. American Society for Microbiology, Washington, D.C.

18. Weaver, R. E., H. W. Tatum, and D. G. Hollis. 1978. The identification of unusual pathogenic gram negative bacteria. Center for Disease Control, Atlanta, Ga. 